\title{
An examination of the self-referent executive processing model of test anxiety: control, emotional regulation, self-handicapping, and examination performance
}

\author{
David W. Putwain ${ }^{1}$ ii
}

Received: 16 October 2017 / Revised: 3 April 2018 / Accepted: 16 April 2018 / Published online: 2 May 2018

(C) The Author(s) 2018

\begin{abstract}
According to the self-referent executive processing (S-REF) model, test anxiety develops from interactions between three systems: executive self-regulation processes, selfbeliefs, and maladaptive situational interactions. Studies have tended to examine one system at a time, often in conjunction with how test anxiety relates to achievement outcomes. The aim of this study was to enable a more thorough test of the S-REF model by examining one key construct from each of these systems simultaneously. These were control (a self-belief construct), emotional regulation through suppression and reappraisal (an executive process), and self-handicapping (a maladaptive situational interaction). Relations were examined from control, emotional regulation, and self-handicapping to cognitive test anxiety (worry), and subsequent examination performance on a high-stakes test. Data were collected from 273 participants in their final year of secondary education. A structural equation model showed that higher control was indirectly related to better examination performance through lower worry, higher reappraisal was indirectly related to worse examination performance through higher worry, and higher self-handicapping was related to worse examination performance through lower control and higher worry. These findings suggest that increasing control and reducing self-handicapping would be key foci for test anxiety interventions to incorporate.
\end{abstract}

Keywords Test anxiety · Worry · Examination performance $\cdot$ Control $\cdot$ Emotional regulation · Self-handicapping

A great many factors are proposed as antecedents of test anxiety including various types of competence beliefs, study habits and skills, importance of the examination, appraisal of the evaluative situation, and approach to coping (Lowe et al. 2008; Segool et al. 2014; Zeidner 1998). In the self-referent executive processing model (Zeidner and Matthews 2005), these

David W. Putwain

D.W.Putwain@ljmu.ac.uk

1 School of Education, Liverpool John Moores University, IM Marsh Campus, Mossley Hill Rd, Liverpool L17 6DB, UK 
various antecedents are grouped into three systems: executive regulatory functions, selfbeliefs, and maladaptive situational interactions. Empirical examinations of test anxiety antecedents have typically studied the constructs associated with these processes in isolation rather than in tandem. As models of test anxiety (e.g., Lowe et al. 2008; Segool et al. 2014; Zeidner 1998; Zeidner and Matthews 2005) propose antecedents would dynamically interact, when examined separately, the relevance of some antecedents may become overstated. Furthermore, although an obvious candidate to investigate as an executive process, studies have yet to examine relations between emotional regulation and test anxiety.

In the present study, these limitations are addressed by examining one key antecedent from each components of the self-referent executive processing model simultaneously in a single analytic model to predict cognitive test anxiety and subsequent examination performance. The three antecedents examined were control (a self-belief), self-handicapping (a maladaptive interaction with the situation), and emotional regulation (an executive process). Control is central to various types of competence beliefs that are relevant to test anxiety (e.g., academic self-efficacy and perceptions of testtaking skills), hence was chosen as being a key indicator of self-belief processes. Selfhandicapping refers to a variety of behaviours that captures how test anxiety can impede one's academic achievement (e.g., strategic withdrawal of effort and avoidance of engaging in examination practice) and hence was chosen to represent at the breadth of maladaptive situational interactions. Emotional regulation was chosen primarily as being the most fundamental executive process in the self-referent executive processing model and, yet, for test anxiety, as being most under-researched.

\section{Cognitive test anxiety and academic achievement}

Test anxiety was defined by Spielberger and Vagg (1995) as a situation-specific trait: that is, a tendency to respond to situations where one's performance will be judged or evaluated with increased worry and emotionality. In non-evaluative situations, highly test anxious persons do not respond with increased worry and emotionality. Worry refers to the cognitive dimension of anxiety. This includes self-preoccupied negative and sometimes catastrophic, thoughts concerning one's performance, failure, and the consequences of failure (Cassady 2010; Sarason 1984; Zeidner 2014). Emotionality refers to the affective-physiological dimension of test anxiety and includes feelings of tension, and anxiety, along with subjective perceptions of autonomic arousal (Schwarzer 1984; Zeidner 2014).

The salience of test anxiety as a psychoeducational construct of importance is largely derived from its associations with various measures of academic achievement including school grades and examination performance (Putwain 2008). A large number of studies, captured in meta-analyses, have shown small, but statistically significant, negative correlations $(r s-0.21$ to -0.31 ) between test anxiety, especially the cognitive component, and academic achievement (Hembree 1988; Chapell et al. 2005; von der Embse et al. 2018). One meta-analysis showed test anxiety to have the fourth largest effect size $\left(r^{+}=-.24\right)$, after self-efficacy, grade goals, and effort regulation, of 42 non-cognitive correlates of academic achievement (Richardson et al. 2012). Importantly, recent studies have shown the negative test anxiety and achievement association remains when controlling for autoregressive relations with prior achievement (Putwain et al. 2016; Steinmayr et al. 2016). 
Studies have shown the negative test anxiety and achievement association to be larger for the cognitive component of test anxiety. Associations with the affective-physiological component are equivocal. Some studies report negative associations, albeit smaller than for the cognitive component, some report null findings, and others positive findings. Accordingly, many studies that examine associations between test anxiety and academic achievement focus solely on the cognitive component of test anxiety (e.g., Cassady 2004; Cassady and Johnson 2002; Putwain and Aveyard 2018). As the present study was concerned with test anxiety as a predictor of examination performance, the current study followed in this tradition and focused solely on the cognitive component of test anxiety as being the most germane to the aim of the present study.

\section{The self-referent executive processing model of test anxiety}

The self-referent executive processing (S-REF) model of test anxiety (Zeidner and Matthews 2005) comprises of three systems: executive regulatory processes, self-beliefs, and maladaptive situational interactions (see Fig. 1). Executive regulatory processes are activated from situational threat comprising of an evaluative situation. These could be external (e.g., being notified of a forthcoming examinations) or internal (e.g., plans for how to prepare for a forthcoming examination). Executive processes control self-regulation of emotion, behaviour, and cognition and include the following elements: (i) an immediate appraisal of the significance of the evaluative situation (i.e., the perceived importance of success or failure), (ii) the implications of failure, (iii) plans for coping, and (iv), metacognitive beliefs about worry. Executive regulatory processes draw on self-beliefs concerning one's academic competence and motivations. In the short term, test anxious worries can be triggered by accessing negative self-beliefs (e.g., that one is not competent in the subject being tested) and choosing counterproductive coping strategies (e.g., rumination, avoidance, or self-blame). Metacognitive beliefs about worry influence monitoring of one's internal state and attempts to intensify or suppress significant thoughts. For instance, a belief that thoughts concerning failure are dangerous would be likely to result in an attempt to suppress such thoughts.

Over the longer term, test anxiety is maintained by maladaptive situational interactions. For instance, the test anxious person might make a strategic withdrawal of effort to protect one's sense of self-worth (e.g., failure can then be attributed to a lack of effort) or engage in other

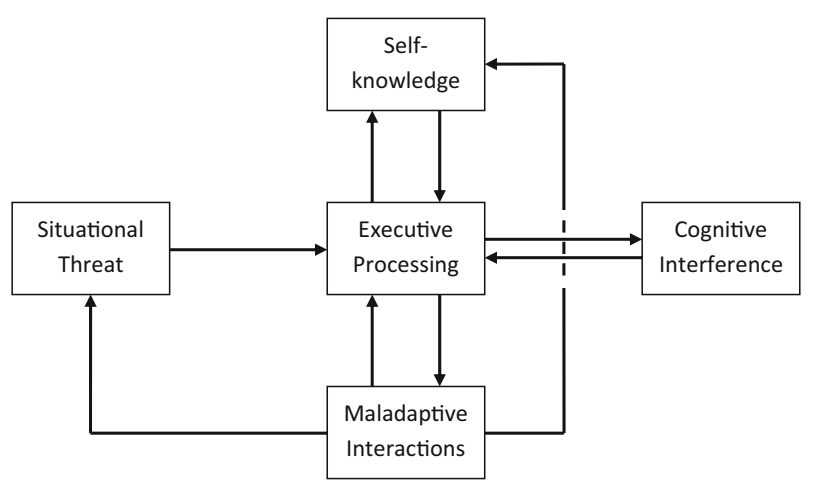

Fig. 1 The self-referent executive processing (S-REF) model of test anxiety (Zeidner and Matthews 2005) 
self-handicapping behaviours, such as avoiding opportunities to improve, practice, or test one's skills and knowledge. Such behaviours link back to self-beliefs and reinforce negative views of one's competence locking the person becomes into a negative self-perpetuating cycle. The outcome of higher test anxiety is cognitive interference leading to disrupted task performance. Although this element is not elaborated on in the S-REF model, cognitive interference theories are well established (e.g., Derakshan and Eysenck 2009, 2011; Wine 1971; Sarason 1988) with empirical support (e.g., Dutke and Stöber 2001; Richards et al. 2000; Owens et al. 2008; Putwain et al. 2014).

The various processes proposed in the S-REF model have been well supported by empirical research. Test anxiety is higher when persons appraise evaluative situations as important but their own competence beliefs to be poor (e.g., Pekrun et al. 2004; Putwain et al. 2010), use avoidant approaches to coping (Putwain et al. 2012, 2016; Stöber 2004), and hold avoidant motivations (e.g., Eum and Rice 2011; Putwain and Symes 2012). Furthermore, test anxiety is enhanced by metacognitive beliefs (e.g., worry is uncontrollable and low confidence in one's cognitive capacities such as memory) and a high degree of metacognitive monitoring (Matthews et al. 1999; O'Carroll and Fisher 2013). Maladaptive situational interactions are shown in negative correlations shown between exam-related worry and effort (e.g., Komarraju and Nadler 2013; Pekrun et al. 2004; studies 3 and 6), positive correlations between test anxiety and procrastination (Gadbois and Sturgeon 2011), helpless attributional style (Bandalos et al. 1995; Cassady 2004), and an attentional bias towards threat stimuli (Putwain et al. 2011).

Although studies have provided support for the three central systems proposed in the SREF model (executive processes, self-beliefs, and maladaptive situational interactions), they are typically examined in isolation rather than in tandem. This may be partly due to the relative complexity of the S-REF model proposing multiple, and sometimes competing, processes. One drawback of this approach, however, is that support for S-REF model remains incomplete and, by not accounting for all three components, may possibly overstate the importance of the particular element included in particular analysis over those excluded or not studied. This concern was addressed in the present study by including one key construct from each of the three systems in the S-REF model. Constructs were chosen as representing the central aspect of the respective system. From self-beliefs this was control, from maladaptive situational interactions this was self-handicapping, and from executive processes this was emotional regulation. Each system was limited to the inclusion of one key construct to avoid overcomplicating the analytic model.

\section{Control}

Self-beliefs in the S-REF model refer to perception of one's abilities in relation to the forthcoming evaluative situation. One construct that has relevance to many types of competence beliefs is perceived control (henceforth referred to as control for brevity). Control is related, but not identical, to competence beliefs, such as academic self-efficacy, academic selfconcept, and perceptions of study and test-taking skills. Rather, such competence beliefs provide the basis for a strong sense of control. Moreover, control can be conceptually differentiated from more generalised competence beliefs by a focus on causal expectancies and attributions. In an academic context, control refers to a prospective belief that one can exert a causal influence over learning activities and outcomes, and the retrospective attribution of academic success or failure to a factor that one can exert a causal influence over (Pekrun 
2006; Pekrun and Perry 2014). For instance, a student who is high in control understands why their level of effort or the strategy utilised resulted in success or failure (Martin 2002, 2007). By contrast, those students who are uncertain in control do not understand why they might have received a good or bad mark for an assessment, or why they could or could not successfully perform the tasks and activities in their lessons (Connell 1985; Martin 2007). Consequently, those who are low in control anticipate failure and, in line with the S-REF model, report higher test anxiety (e.g., Pekrun et al. 2004; Putwain and Aveyard 2018).

\section{Self-handicapping}

In the S-REF model, maladaptive person-situation interactions refer to ways that the student avoids evaluative situations, opportunities to develop their competence that might be evaluated at a later point, or making an effort to develop their competence that might be evaluated at a later point. These various forms of maladaptive person-situation interactions are effectively captured in the construct of self-handicapping. Self-handicapping refers to a repertoire of behaviours that impede or provide obstacles to one's academic achievement (Martin 2007; Martin et al. 2001). These behaviours can include procrastination, deliberately creating circumstances that will negatively impact on one's performance (e.g., losing one's study materials), strategic withdrawal of effort, and avoiding practicing one's skills or engaging in examination preparations. These behaviours protect one's sense of self-worth from anticipated failure by deflecting attributions away from a lack of ability (Covington 2009). Although related to attributions of failure, self-handicapping does not constitute an attributional style itself, but a behavioural strategy used prior to an examination to pre-empt particular attributions (Martin et al. 2003). In line with the S-REF model, self-handicapping is positively associated with test anxiety (Thomas and Gadbois 2007) and fear of failure (Elliot and Church 2003), a cognate construct to that of test anxiety.

\section{Emotional regulation}

Executive processes in the S-REF model control self-regulation of emotion, cognition, and behaviour. Of these three, the most directly relevant to the level and intensity of anxiety is emotional regulation (Campbell-Sills and Barlow 2007; Cisler et al. 2010. Emotional regulation refers to one's ability to access, monitor, and control (reduce or increase) emotional reactions (Gross and Thompson 2007; Thompson 1994). This can include reducing as well as sustaining the intensity and durations of emotions (Calkins and Hill 2007; Cole et al. 1994). Gross' (1998) model of emotional regulation proposes two processes: cognitive reappraisal and expressive suppression. Cognitive reappraisal involves the optimistic re-evaluation of a situation to change its emotional impact, and expressive suppression involves the inhibition of emotionally expressive behaviours. In response to stressful events, reappraisal is associated with increased positive affect and decreased negative affect (John and Gross 2004). In contrast, suppression is associated with reduced positive affect while leaving the experience of negative emotions intact (Gross and John 2003; Srivastava et al. 2009). In line with the S-REF model, thought suppression is positively associated with test anxiety (Rost and Schermer 1997) and the anxiety associated with an evaluated speech task (Egloff et al. 2006). Although studies have yet to establish empirical relations between reappraisal and test anxiety, cognitive 
restructuring is viewed as a credible site of intervention for reducing test anxiety (Brown et al. 2011) and following Gross' (1998) model might be expected to be related to lower test anxiety. In the abovementioned speech task, reappraisal was negatively associated with speaking anxiety (Egloff et al. 2006).

\section{Aim of the current study}

Previous studies have highlighted the importance of executive processes, self-beliefs, and maladaptive situational interactions, in test anxiety (e.g., Komarraju and Nadler 2013; Matthews et al. 1999; Pekrun et al. 2004). These studies, however, have examined these systems in isolation whereas, theoretically speaking, these systems are related. In order to address this limitation, the aim of the current study was to simultaneously examine the three key systems of the S-REF model, executive processes (emotional regulation), self-belief (control), and maladaptive situational interactions (self-handicapping), on the cognitive component of test anxiety (worry). Worry would then be expected to negatively associate with examination performance. Thus, a model is proposed where emotional regulation (reappraisal and suppression), control, and self-handicapping are indirectly related to examination performance, mediated by worry (see Fig. 2).

In the S-REF model, self-beliefs (control) and maladaptive situational interactions (selfhandicapping) are related in a bidirectional fashion with executive regulatory processes (reappraisal and suppression). Accordingly, in the analytic model (see Fig.2), relations between control and reappraisal/suppression, and between self-handicapping and reappraisal/suppression, were represented in as covariances. Furthermore, following the S-REF model, the relation from maladaptive situational interactions (self-handicapping) to self-beliefs (control) is unidirectional and so is represented in the analytic model as a structural path. Thus, selfhandicapping is related to worry directly or indirectly, via control.

As female persons report higher test anxiety (Putwain 2007; Putwain and Daly 2014), less use of suppression (Gross and John 2003), and outperform male students in English secondary education (Bramley et al. 2015), gender was included as a covariate. Furthermore, test anxiety is higher (Putwain 2007), and examination performance lower, in deprived groups

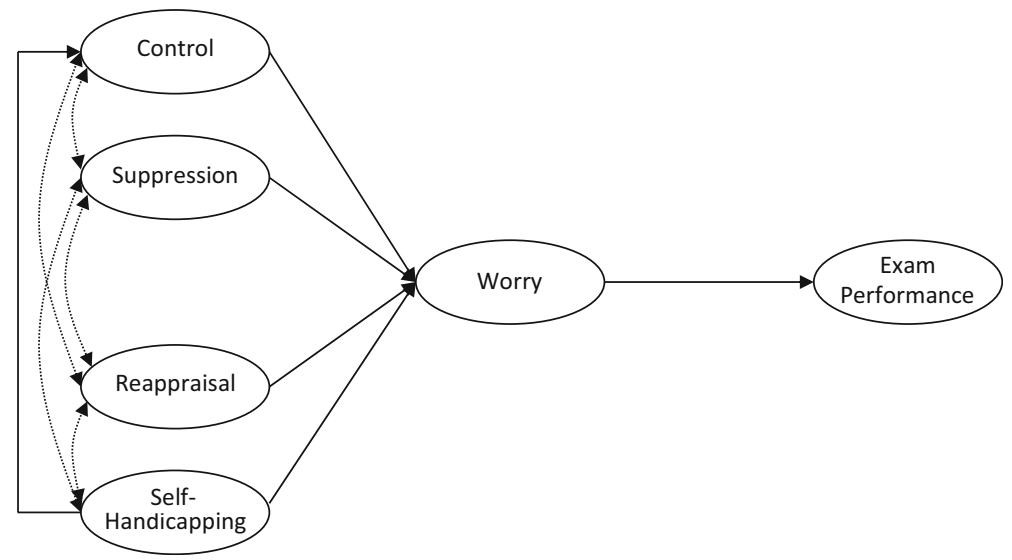

Fig. 2 Worry mediates the relations between control, self-handicapping, reappraisal and suppression, and examination performance. Solid lines represent structural paths $(\beta \mathrm{s})$, and dashed lines represent correlations $(r \mathrm{~s})$ 
(Department for Children, Schools, and Families 2009), and test anxiety is lower in older students (Putwain 2007), age and free school meals (as a proxy for low income) were also included as covariates. The following hypotheses were examined:

H1: Worry will be predicted by suppression and self-handicapping (positively) and control (negatively). It is tentatively suggested that cognitive reappraisal will negatively predict worry.

$H 2$ : Worry will negatively predict examination performance.

H3: Indirect relations between control, self-handicapping, cognitive reappraisal, suppression, and examination performance will be mediated by worry; an additional indirect relation between self-handicapping and examination performance will be serially mediated by control and worry.

\section{Method}

\section{Participants}

Data were collected from 273 participants $($ male $=120$, female $=153$ ), from two English secondary schools, who were in their final year of compulsory secondary education (year 11). The mean age of participants in this sample was 15.5 years $(\mathrm{SD}=0.50)$, and $n=40$ were eligible for free school meals (as a proxy for low income). In comparison to other English schools, student performance on school exit examinations (a fundamental accountability measure in the English educational system) was slightly better than the English average: the proportion of students achieving minimum pass grades in five key subjects (English, mathematics, science, one modern foreign language, and one humanities) was $28.5 \%$ compared to the English national average of $21.3 \%$. A small proportion of data was missing $(2.1 \%$ of the variables) that were unrelated to substantive study variables or covariates. In subsequent analyses, missing data were handled using full information maximum likelihood.

\section{Measures}

Emotional regulation was measured using the 12-item Emotion Regulation Questionnaire for Children and Adolescents (Gullone and Taffe 2012). This instrument comprises two scales. These are cognitive appraisal (eight items) and suppression (four items). Exemplar items include 'When I want to feel happier, I think about something different' (cognitive reappraisal) and 'I control my feelings by not showing them' (suppression). Participants responded to items on a five-point scale (one = 'strongly disagree', five = 'strongly agree') such that a higher score represents greater use of cognitive appraisal or suppression. Internal consistency, stability, and construct and predictive validity of data collected using this scale have been shown in several studies (e.g., Gresham and Gullone 2012; Gullone and Taffe 2012). In the present study, the internal consistency coefficients were acceptable (see Table 1).

Control and self-handicapping were measured using scales from the Motivation and Engagement Scale (Martin 2007). Each scale comprised of four items (e.g., 'When I get a bad mark I'm I am often unsure how to avoid getting that mark again' for control and 'Some students purposely get involved in lots of activities to avoid revising for exams. How true is this of you?' for self-handicapping). Participants responded to items on a five-point scale (one 
Table 1 Descriptive statistics for control, self-handicapping, suppression, reappraisal, worry, and examination performance

\begin{tabular}{llllllll}
\hline & Range & Mean & SD & $\alpha$ & Skewness & Kurtosis & Factor loadings \\
\hline Worry & $1-4$ & 2.74 & 0.51 & 0.71 & -0.05 & -0.54 & $0.57-0.65$ \\
Control & $1-5$ & 3.06 & 0.87 & 0.76 & 0.17 & -0.42 & $0.48-0.73$ \\
Self-handicapping & $1-5$ & 2.57 & 0.94 & 0.78 & 0.39 & -0.35 & $0.56-0.80$ \\
Suppression & $1-5$ & 3.41 & 0.73 & 0.72 & -0.63 & 0.40 & $0.46-0.66$ \\
Reappraisal & $1-5$ & 3.16 & 0.75 & 0.76 & -0.10 & 0.09 & $0.50-0.65$ \\
Examination performance & $1-8$ & 4.97 & 1.50 & - & -0.30 & -0.02 & - \\
\hline
\end{tabular}

$=$ strongly disagree, five $=$ strongly agree), and scores on the control items were reversed to facilitate interpretation. Thus, a higher score would represent stronger control beliefs and greater use of self-handicapping behaviours. The internal consistency, construct, and predictive validity, of data collected using these scales, have been extensively documented in previous studies (e.g., Green et al. 2007; Plenty and Heubeck 2013). In the present study, the internal consistency coefficients were acceptable (see Table 1).

Examination performance was measured using an aggregate of student performance on General Certificate of Secondary Education (GCSE) examinations in English, mathematics, and science. GCSE are high-stakes exit examinations taken at the end of compulsory schooling aged 16 years. Student performance can, and does, influence access to post-compulsory education and training and entry to the labour market (Maguire 2010; Unwin 2010). GCSE examinations were marked graded by an external awarding body using an eight-point letter system ( $A^{*}, A, B, C$, and so on to grade $G$ ). Grade $C$ is considered to be a minimum pass grade. These scores were converted to a numerical equivalent $\left(A^{*}=8, A=7, B=6, C=5, G\right.$ $=1$ ) such that a higher score represented better examination performance. As examinations were marked and graded by an external awarding body, it is not possible to report the internal consistency. Previous studies, however, have shown high internal consistency of marking (Bramley and Dhawan 2011) that corresponds with that of external evaluators (Dhawan and Branley 2013).

\section{Procedure}

Self-report data were collected during a period of the school timetable used for administrative purposes (in English education, this is referred to as form period) so not to interfere with students regular instruction. A questionnaire pack, including worry, control, self-handicapping, and emotional regulation, items presented in a randomised order, demographic questions, and information about ethics, was administered by trained research assistants and took approximately 15 min to complete. Questionnaire data were collected in the February of the school year, approximately 3-4 months before GCSE examinations were taken (during May and June). For ethical purposes, participants were provided with information about the purpose of the study, told that participation was voluntary and how to retrospectively withdraw data, and asked for permission to allow the school to release their GCSE grades in English, mathematics, and science. To keep data anonmyised, if participants provided permission to release GCSE grades, they were asked to provide their unique examination candidate number (this is a series of numbers allocated by the external awarding body) that was used to match questionnaire data with subsequent examination grades. The project was approved by an institutional ethics 
committee. Written permission to collect data was provided by the head teacher of the participating schools and individual participants. Passive consent (i.e., opt-out) was provided by parents/carers of participants.

\section{Results}

\section{Descriptive statistics and bivariate correlations}

Descriptive statistics for control, self-handicapping, suppression, reappraisal, worry, and examination performance are shown in Table 1 . All variables were normally distributed and within acceptable limits of skewness and kurtosis $( \pm 1)$. The internal reliability coefficients were acceptable (Cronbach's $\alpha \geq 0.71$ ), and standardised factor loadings, from the measurement model described as follows, were all satisfactory $(\lambda \geq 0.48)$. In order to generate latent bivariate correlations, and check the properties of constructs prior to structural equation modelling, a measurement model was built and assessed using a confirmatory factor analysis. The measurement model included worry (six items), control, self-handicapping, and reappraisal (four items each), and suppression (eight items), as latent constructs. Examination performance was modelled as a single-item latent construct $(\lambda=0.9, \varepsilon=0.1)$. Gender $(0=$ male, $1=$ female), age, and free school meals $(0=$ no free school meals, $1=$ free school meals $)$ were included as covariates.

The measurement model was assessed using a variety of model fit indices including the root mean square error of approximation (RMSEA), standardised root mean square residual (SRMR), comparative fit index (CFI), and Tucker-Lewis index (TLI). Hu and Bentler (1999) suggest a model fit is indicated by RMSEA $<0.05$, SRMR $<0.08$, and CFI and TLI $>0.95$; however, such cut-off values should not be applied too strictly when working with reallife data (Heene et al. 2011). The measurement model, estimated using maximum likelihood in Mplus v.8 (Muthén and Muthén 2017), showed a largely good fit to the data, $\chi^{2}(220)=$ $273.07, p<.001, \mathrm{CFI}=0.954, \mathrm{TLI}=0.942$, $\mathrm{RMSEA}=0.030, \mathrm{SRMR}=0.047$ and no obvious source of misspecification, and so, latent bivariate correlations were examined (see Table 2). Worry was correlated negatively with control and examination performance and positively with self-handicapping, suppression, and reappraisal. Control was positively correlated with examination performance and negatively correlated with self-handicapping, suppression, and reappraisal. Female students reported greater worry and reappraisal and lower control. Older students reported lower worry.

\section{Structural equation modelling}

A structural equation model was built that specified paths from control, self-handicapping, suppression, and reappraisal, to worry, from self-handicapping to control, and from worry to examination performance. Gender and age were included as covariates, but not free school meals, as no statistically bivariate correlations were shown in Table 2. This, theoretically derived, fully mediated model was tested competitively against an alternative partially mediated model. The partially mediated model included direct paths from control, self-handicapping, suppression, and reappraisal to examination performance. All models were estimated using maximum likelihood in Mplus v.8 (Muthén and Muthén 2017) and assessed using the same model fit indices and criteria as the measurement model. 
Table 2 Latent bivariate correlations for substantive study variables (control, self-handicapping, suppression, reappraisal, worry, and examination performance) and covariates (gender, age, and free school meals)

\begin{tabular}{|c|c|c|c|c|c|c|c|c|c|}
\hline & 1. & 2. & 3. & 4. & 5. & 6. & 7. & 8. & 9. \\
\hline 1. Worry & - & $-0.65^{* * *}$ & $0.20 *$ & $0.29 *$ & $0.46^{* * *}$ & $-0.26^{* *}$ & $0.27 * * *$ & $-0.18^{*}$ & -0.04 \\
\hline 2. Control & & - & $-0.35 * * *$ & $-0.35^{* * *}$ & $-0.29 * * *$ & $0.30^{* * *}$ & $-0.34 * * *$ & -0.02 & 0.01 \\
\hline $\begin{array}{l}\text { 3. } \\
\text { Self-- } \\
\text { handicapping }\end{array}$ & & & - & $0.20 *$ & $0.25^{* * *}$ & -0.04 & -0.06 & -0.11 & -0.01 \\
\hline 4. Suppression & & & & - & $0.25 *$ & -0.11 & 0.13 & -0.03 & 0.02 \\
\hline 5. Reappraisal & & & & & - & -0.08 & $0.17 *$ & -0.07 & -0.09 \\
\hline $\begin{array}{l}\text { 6. Examination } \\
\text { performance }\end{array}$ & & & & & & - & -0.02 & 0.07 & 0.04 \\
\hline 7. Gender & & & & & & & - & -0.02 & 0.05 \\
\hline 8. Age & & & & & & & & - & 0.04 \\
\hline $\begin{array}{l}\text { 9. Free school } \\
\text { meals }\end{array}$ & & & & & & & & & - \\
\hline
\end{tabular}

Gender coded $0=$ male, $1=$ female. FSM (free school meals) coded $0=$ no FSM, $1=$ FSM $* p<.05 ; * * p<.01 ; * * * p<.001$

The fully mediated model showed a largely good fit to the data: $\chi^{2}(209)=263.18, p<.001$, $\mathrm{CFI}=0.953$, TLI $=0.944$, RMSEA $=0.031, \mathrm{SRMR}=0.048$. In comparison, the partially mediated model, $\chi^{2}(205)=257.08, p<.001, \mathrm{CFI}=0.955$, TLI $=0.945$, RMSEA $=0.030$, $\mathrm{SRMR}=0.047$, showed a slight improvement in model fit $(\triangle \mathrm{CFI}=0.002, \Delta \mathrm{TLI}=0.001$, $\triangle \mathrm{RMSEA}=0.001$, and $\triangle \mathrm{SRMR}=0.001$ ) but was not a statistically significant improvement: $\Delta \chi^{2}(4)=6.1, p=.19$. Given that the partially mediated model did not offer a substantial advantage, the fully mediated model was preferred as more parsimonious and restrictive of the two. Model fit indices are reported from this model (see Fig. 3).

Higher control predicted lower $(\beta=-0.61, p<.001)$, and reappraisal higher $(\beta=0.31$, $p<.001)$, worry. Self-handicapping and suppression were not statistically significant predictors of worry $(p \mathrm{~s}>.05)$. Higher self-handicapping predicted lower control $(\beta=-0.38$, $p<.001)$ and higher worry predicted lower examination performance $(\beta=-0.23, p=.002)$. Of the covariates included in the model, female students reported lower control $(\beta=-0.34$,

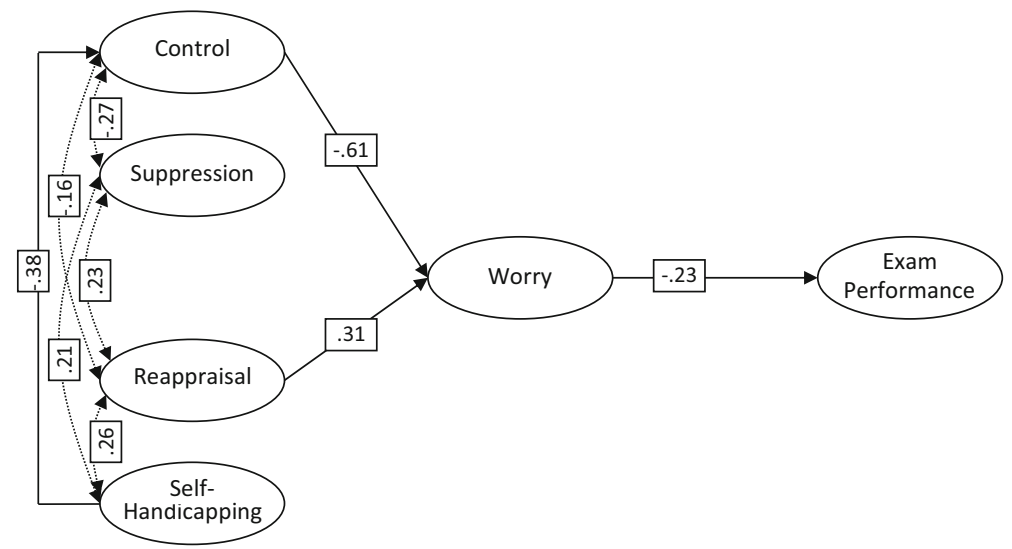

Fig. 3 The fully mediated SEM to examine paths from control, self-handicapping, reappraisal, and suppression to worry and from worry to examination performance. Solid lines represent structural paths $(\beta \mathrm{s})$, and dashed lines represent correlations $(r \mathrm{~s})$ 
$p<.001)$, and higher reappraisal $(\beta=0.16, p=.03)$, and older students reported lower worry $(\beta=-0.18, p=.006)$. Coefficients for all other covariates were not statistically significant $(p \mathrm{~s}>.05)$.

Indirect paths were examined by using 1000 bootstrapped draws to create $95 \%$ confidence intervals around the beta estimate. A statistically significant indirect path (at $p<.05$ ) is shown when the confidence intervals do not cross zero. Statistically significant indirect paths were shown from control to examination performance, via worry $(\beta=0.14, S E=0.05,95 \% \mathrm{CI}$ $[0.06,0.22])$, reappraisal to examination performance, via worry $(\beta=-0.07, S E=0.03,95 \%$ $\mathrm{CI}[-0.02,-0.12])$, and self-handicapping to examination performance via control and worry $(\beta=-0.05, S E=0.02,95 \%$ CI $[-0.02,-0.09])$. Indirect paths from self-handicapping and suppression to examination performance, via worry, were not statistically significant at $p<.05$ as $95 \%$ CIs crossed zero.

\section{Discussion}

The aim of this study was to examine constructs pertaining to the three central systems proposed in the S-REF model of test anxiety (Zeidner and Matthews 2005) in a single model to predict cognitive test anxiety (worry) and subsequently examination performance. These were control, as a key indicator of self-beliefs, self-handicapping as a key indicator of maladaptive situational interactions, and emotional regulation (reappraisal and suppression) as a key indicator of executive processes. Results showed that control negatively predicted,worry (partially supporting $H 1$ ); however, suppression and self-handicapping were not related to worry. Although it was tentatively predicted that reappraisal would negatively predict worry the opposite was found; reappraisal positively predicted worry. Worry negatively predicted examination performance (supporting H2). Higher control was related to a better examination performance through reduced worry, higher reappraisal was related to a lower examination performance through increased worry, and higher self-handicapping was related to a lower examination performance serially through lower control and higher worry (partly supporting $H 3$ ).

It was tentatively predicted that cognitive reappraisal would be negatively related to worry; however, findings showed the opposite; cognitive reappraisal was positively associated with worry. This would seem contrary to the theoretical predictions of Gross' (1998) model, whereby the situation is optimistically re-evaluated in order to reduce anxiety and the findings of Egloff et al. (2006) who found speaking anxiety was negative associated with reappraisal. Studies from the individual differences literature, however, have found trait anxiety to correlate positively with cognitive reappraisal strategies (Garnefski et al. 2001) and that high general trait anxiety is only negatively related to particular types of cognitive reappraisal such as using the situation as a growth opportunity and putting the situation into a new perspective (Martin and Dahlen 2005). Other types of cognitive reappraisal (acceptance, positive refocusing, and re-planning) were unrelated to anxiety.

While these findings highlight that the relation between anxiety and cognitive reappraisal is not unequivocal, it does not explain why positive relations were shown in this study. One possibility is that it is not which emotional regulation strategies are used but whether such strategies are used flexibly (Bonanno et al. 2004; Cheng 2001). For instance in circumstances when stressors were perceived to be controllable, cognitive reappraisal was positively related to distress, and when stressors were perceived to be uncontrollable, cognitive reappraisal was negatively related to distress 
(Troy et al. 2013). When faced with a situation such as taking compulsory high-stakes school leaving examinations (like the GCSE examinations that participants in this study faced) where participants are able to exercise control over their study strategies, effort, and persistence, the most effective strategies may be problem focused (see Dixon-Gordon et al. (2015)).Optimistic reappraisals, in themselves, will not change the likelihood of success or failure and so may actually continue to prompt self-belief processes (i.e., low control or competence beliefs) that result in worry.

An indirect positive association was shown from control to examination performance, via lower worry, and a negative association from cognitive reappraisal to examination performance, via greater worry. It is notable that the SEM including direct paths from antecedents to examination performance did not offer a statistically superior model fit than the total mediation model shown in Fig. 1. Although, theoretically (see Martin (2007)), control might be expected to relate to examination performance via additional mechanisms to that of worry (that would be represented by a statistically significant direct relationship between control and examination performance as well as the indirect relationship mediated by worry), this was not the case in the present sample. In the SEM, when the associations between all antecedents were controlled, self-handicapping and suppression did not show statistically significant relations with worry and hence no indirect relations with examination performance.

This is a notable finding as when examined in isolation (see $r \mathrm{~s}$ in Table 2), self-handicapping and suppression did show statistically significant relations with worry in line with previous research (e.g., Thomas and Gadbois 2007; Rost and Schermer 1997). Following the S-REF model, where maladaptive situational interactions help to shape self-beliefs, a statistically significant negative indirect path was found from higher self-handicapping to lower examination performance mediated initially via lower control and downstream, by higher worry. With regard to suppression, the likely reason is the variance shared with control, reappraisal, and self-handicapping. That is, persons who use suppression as a regulatory strategy also, to some degree, use reappraisal as a regulatory strategy, have lower perceived control, and use more self-handicapping behaviours. Once the variance shared with control, reappraisal, and self-handicapping is accounted for, there is insufficient remaining to significantly predict control. This does not render suppression as a meaningless predictor of worry. Rather, its relative contribution is reduced when examined in conjunction with control, reappraisal, and self-handicapping, thus reinforcing the value of examining multiple components of the S-REF model simultaneously.

\section{Limitations and suggestions for future research}

Although this study is the first to examine the three systems of the S-REF model (self-beliefs, executive processes, and maladaptive situational interactions) in a single analysis, there are three notable limitations to highlight. First, control, emotional regulation, and self-handicapping were measured concurrently with worry. In such cross-sectional designs, there will always be a question over directionality unless antecedents are separated over time from the mediating variable (Kenny et al. 1998), in this case worry. This presents a conundrum for researchers examining the S-REF model where interactions between certain processes (e.g., executive processes and self-beliefs) may occur sufficiently fast as to, for practical purposes, appear simultaneous. A possible solution would be for future research to take repeated, situationally sensitive, single-item measurements of salient SREF model constructs from individuals to capture dynamic interactions as they unfold over time (see Murayama et al. (2017)).

Second and related, autoregressive relations with prior achievement or examination performance were not controlled for. In such designs, there will always be a question whether the 
relations with subsequent examination performance are an artefact of prior examination performance or achievement (Little et al. 2007). Thus, a more robust examination of the associates from the S-REF model to examination performance could examine indirect relations from self-beliefs, executive processes, and maladaptive situational interactions, through worry, to examination performance over and above the variance accounted for by prior achievement or examination performance.

Finally, only one construct related to each of the three processes in the S-REF model was selected. There are many other constructs, related to these processes, not included in the present study. Self-beliefs include subject-specific or domain-general competence perceptions, such as academic self-concept or academic self-efficacy (e.g., Preiss et al. 2006), perceptions of study and test-taking skills (e.g., Topman et al. 1992), and perfectionism (e.g., Eum and Rice 2011). Executive processes include appraisals of the personal importance of the forthcoming examination or test (e.g., Boehme et al. 2017), metacognition (e.g., O'Carroll and Fisher 2013), and coping (e.g., Stöber 2004). Maladaptive situational interactions include avoidance behaviours (e.g., Cohen et al. 2008) and attentional bias towards threat (Dong et al. 2017). Future research should consider including such constructs either as alternatives to those included in the present study or in a more complex examination of the S-REF model (or indeed other test anxiety models) to include carefully chose multiple constructs simultaneously for each process that combine in a complimentary fashion. Despite these limitations, this study provides a useful stepping stone to more complex studies in showing how constructs relating to different systems can be usefully combined in a single analytic model.

\section{Conclusion}

The current study examined constructs (emotional regulation, control, and self-handicapping) related to the three systems of the S-REF model of test anxiety (executive processes, selfbeliefs, and maladaptive situational interactions, respectively) simultaneously in a single analysis. Control and reappraisal were related to worry and indirectly related to examination performance. Self-handicapping was indirectly related to worry and subsequently examination performance, through control. These constructs might, therefore, be useful foci for test anxiety interventions. However, given that equivocal relations are reported in the literature between reappraisal and anxiety and the suggestion made in this paper that reappraisal would be unlikely to change worry without a corresponding change in self-beliefs and maladaptive situational interactions, it would be prudent to limit this suggestion for intervention foci to control and self-handicapping only.

Practitioners can ensure that feedback given to students is strategy focused (i.e., makes an explicit link between the student's approach to a piece of work and their eventual mark or grade) to assist the student understanding the link between strategy and outcome. This will help students to build their understanding of which strategies are effective and their sense of control over their learning and its outcomes. Practitioners can also help students to reduce academic self-handicapping by avoiding attributing success or failure, in written or verbal feedback to ability (i.e., telling a student they are clever following a good piece of work). Instead, feedback should relate the outcome to effort and strategy (i.e., telling a student that their approach was effective). Such strategies would help to reduce cognitive test anxiety (worry) and the negative association with examination performance.

Compliance with ethical standards The project was approved by an institutional ethics committee. 
Open Access This article is distributed under the terms of the Creative Commons Attribution 4.0 International License (http://creativecommons.org/licenses/by/4.0/), which permits unrestricted use, distribution, and reproduction in any medium, provided you give appropriate credit to the original author(s) and the source, provide a link to the Creative Commons license, and indicate if changes were made.

\section{References}

Bandalos, D. L., Yates, K., \& Thorndike-Christ, T. (1995). Effects of math self-concept, perceived self-efficacy, and attributions for failure and success on test anxiety. Journal of Educational Psychology, 87(4), 611-623. https://doi.org/10.1037/0022-0663.87.4.611.

Boehme, K. L., Goetz, T., \& Preckel, F. (2017). Is it good to value math? Investigating mothers' impact on their children's test anxiety based on control-value theory. Contemporary Educational Psychology, 51, 11-21. https://doi.org/10.1016/j.cedpsych.2017.05.002.

Bonanno, G. A., Papa, A., Lalande, K., Westphal, M., \& Coifman, K. (2004). The importance of being flexiblethe ability to both enhance and suppress emotional expression predicts long-term adjustment. Psychological Science, 15(7), 482-487. https://doi.org/10.1111/j.0956-7976.2004.00705.x.

Bramley, T., \& Dhawan, V. (2011). Estimates of reliability of qualifications. Coventry: Ofqual.

Bramley, T., Vidal Rodeiro, C.L., \& Vitello, S. (2015). Gender differences in GCSE. Cambridge Assessment Research Report. Cambridge: Cambridge Assessment.

Brown, L. A., Forman, E. M., Herbert, J. D., Hoffman, K. L., Yuen, E. K., \& Goetter, E. M. (2011). A randomized controlled trial of acceptance-based behavior therapy and cognitive therapy for test anxiety: a pilot study. Behavior Modification, 35(1), 31-53. https://doi.org/10.1177/0145445510390930.

Campbell-Sills, L., \& Barlow, D. H. (2007). Incorporating emotion regulation into conceptualizations and treatments of anxiety and mood disorders. In J. J. Gross (Ed.), Handbook of emotion regulation (pp. 542559). New York: Guilford Press.

Cassady, J. C. (2004). The influence of cognitive test anxiety across the learning-testing cycle. Learning and Instruction, 14(6), 569-592. https://doi.org/10.1016/j.learninstruc.2004.09.002.

Cassady, J. C. (2010). Test anxiety: contemporary theories and implications. In J. C. Cassady (Ed.), Anxiety in schools (pp. 7-26). New York: Peter Lang.

Cassady, J. C., \& Johnson, R. E. (2002). Cognitive test anxiety and academic performance. Contemporary Educational Psychology, 27(2), 270-295. https://doi.org/10.1006/ceps.2001.1094.

Chapell, M. S., Blanding, Z. B., Silverstein, M. E., Takahashi, M., Newman, B., Gubi, A., \& McCann, N. (2005). Test anxiety and academic performance in undergraduate and graduate students. Journal of Educational Psychology, 97(2), 268-274. https://doi.org/10.1037/0022-0663.97.2.268.

Cheng, C. (2001). Assessing coping flexibility in real-life and laboratory settings: a multimethod approach. Journal of Personality and Social Psychology, 80(5), 814-833. https://doi.org/10.1037//3415.80.5.814.

Cisler, J. M., Olatunji, B. O., Feldner, M. T., \& Forsythh, J. T. (2010). Emotion regulation and the anxiety disorders: an integrative review. Journal of Psychopathology and Behavioral Assessment, 32(1), 68-82. https://doi.org/10.1007/s10862-009-9161-1.

Cohen, M., Ben-Zur, H., \& Rosenfeld, M. J. (2008). Sense of coherence, coping strategies, and test anxiety as predictors of test performance among college students. International Journal of Stress Management, 15(3), 289-303. https://doi.org/10.1037/1072-5245.15.3.289.

Cole, P. M., Michel, M. K., \& Teti, L. O. (1994). The development of emotion regulation and dysregulation: a clinical perspective. Monographs of the Society for Research in Child Development, 59(2/3), 73-100. https://doi.org/10.2307/1166139.

Connell, J. P. (1985). A new multidimensional measure of children's perceptions of control. Child Development, 56(4), 1018-1041. https://doi.org/10.2307/1130113.

Covington, M. (2009). Self-worth theory. In K. R. Wentzel \& D. B. Miele (Eds.), Handbook of motivation at school (pp. 141-169). New York: Routledge.

Department for Children, Schools, and Families. (2009). Deprivation and education: the evidence on pupils in England, Foundation Stage to Key Stage 4. London: HMSO.

Derakshan, N., \& Eysenck, M. W. (2009). Anxiety, processing efficiency and cognitive performance: new developments from attentional control theory. European Psychologist, 14(2), 168-176. https://oi. org/10.1027/1016-9040.14.2.168.

Derakshan, N., \& Eysenck, M. W. (2011). New perspectives in attentional control theory. Personality and Individual Differences, 50(7), 955-960. https://doi.org/10.1016/j.paid.2010.08.019.

Dhawan, V., \& Branley, T. (2013). Estimation of inter-rator reliability (Report for Ofqual). Cambridge: Cambridge Assessment. 
Dixon-Gordon, K. L., Aldao, A., \& De Los Reyes, A. (2015). Emotion regulation in context: examining the spontaneous use of strategies across emotional intensity and type of emotion. Personality and Individual Differences, 86, 271-276. https://doi.org/10.1016/j.paid.2015.06.011.

Dong, Y., De Beuckelaer, A., Yu, L., \& Zhou, R. (2017). Eye-movement evidence of the time-course of attentional bias for threatening pictures in test-anxious students. Cognition and Emotion, 31(4), 781-790. https://doi.org/10.1080/02699931.2016.1152953.

Dutke, S., \& Stöber, J. (2001). Test anxiety, working memory and cognitive performance: supportive effects of sequential demands. Cognition andEmotion, 15(3), 381-389. https://doi.org/10.1080/02699930125922.

Egloff, B., Schmukle, S. C., Burns, L. R., \& Schwerdtfeger, A. (2006). Spontaneous emotion regulation during evaluated speaking tasks: associations with negative affect, anxiety expression, memory, and physiological responding. Emotion, 6, 356-366. https://doi.org/10.1037/1528-3542.6.3.356.

Elliot, A. J., \& Church, M. A. (2003). A motivational analysis of defensive pessimism and self-handicapping. Journal of Personality, 71(3), 369-396. https://doi.org/10.1111/1467-6494.7103005.

Eum, K., \& Rice, K. G. (2011). Test anxiety, perfectionism, goal orientation, and academic performance. Anxiety, Stress, \& Coping, 24(2), 167-178. https://doi.org/10.1080/10615806.2010.488723.

Eum. K., \& Rice, K. G. (in press). Test anxiety, perfectionism, goal orientation and academic performance. Anxiety, Stress and coping, 24(2), 167-178. https://doi.org/10.1080/10615806.2010.488723.

Gadbois, S. A., \& Sturgeon, R. D. (2011). Academic self-handicapping: relationships with learning specific and general self-perceptions and academic performance over time. British Journal of Educational Psychology, 81(2), 207-222. https://doi.org/10.1348/000709910X522186.

Garnefski, N., Kraaij, V., \& Spinhoven, P. (2001). Negative life events, cognitive emotion regulation and emotional problems. Personality and Individual Differences, 30(8), 1311-1327. https://doi.org/10.1016 /S0191-8869(00)00113-6.

Green, J., Martin, A. J., \& Marsh, H. W. (2007). Motivation and engagement in English, mathematics and science high school subjects: towards an understanding of multidimensional domain specificity. Learning and Individual Differences, 17(3), 269-279. https://doi.org/10.1016/j.lindif.2006.12.003.

Gresham, D., \& Gullone, E. (2012). Emotion regulation strategy use in children and adolescents: the explanatory roles of personality and attachment. Personality and Individual Differences, 52(5), 616-621. https://oi. org/10.1016/j.paid.2011.12.016.

Gross, J. J. (1998). The emerging field of emotion regulation: an integrative review. Review of General Psychology, 2(3), 271-299. https://doi.org/10.1037/1089-2680.2.3.271.

Gross, J. J., \& John, O. P. (2003). Individual differences in two emotion regulation processes: implications for affect, relationships, and wellbeing. Journal of Personality and Social Psychology, 85(2), 348-362. https://doi.org/10.1037/0022-3514.85.2.348.

Gross, J. J., \& Thompson, R. A. (2007). Emotion regulation: Conceptual foundations. In J. J. Gross (Ed.), Handbook of emotion regulation (pp. 3-24). New York: Guilford Press.

Gullone, E., \& Taffe, J. (2012). The Emotion Regulation Questionnaire for Children and Adolescents (ERQ-CA): a psychometric evaluation. Psychological Assessment, 24(2), 409-417. https://doi.org/10.1037/a0025777.

Heene, M., Hilbert, S., Draxler, C., Ziegler, M., \& Bühner, M. (2011). Masking misfit in confirmatory factor analysis by increasing unique variances: a cautionary note on the usefulness of cutoff values of fit indices. Psychological Methods, 16(3), 319-336. https://doi.org/10.1037/a0024917.

Hembree, R. (1988). Correlates, causes, effects and treatment of test anxiety. Review of Educational Research, 58(1), 47-77. https://doi.org/10.3102/00346543058001047.

Hu, L., \& Bentler, P. M. (1999). Cutoff criteria for fit indexes in covariance structure analysis: conventional criteria versus new alternatives. Structural Equation Modeling, 6(1), 1-55. https://oi.org/10.1080/10705519909540118.

John, O. P., \& Gross, J. J. (2004). Healthy and unhealthy emotion regulation: personality processes, individual differences, and life span development. Journal of Personality, 72(6), 1301-1334. https://doi.org/10.1111 j.1467-6494.2004.00298.x.

Kenny, D. A., Kashy, D. A., \& Bolger, N. (1998). Data analysis in social psychology. In D. Gilbert, S. Fiske, \& G. Lindzey (Eds.), The handbook of social psychology (pp. 233-265). Boston: McGraw-Hill.

Komarraju, M., \& Nadler, D. (2013). Self-efficacy and academic achievement: why do implicit beliefs, goals, and effort regulation matter? Learning and Individual Differences, 25, 67-72. https://doi.org/10.1016/j.lindif.2013.01.005.

Little, T. D., Preacher, K. J., Selig, J. P., \& Card, N. A. (2007). New developments in latent variable panel analyses of longitudinal data. International Journal of Behavioral Development, 31(4), 357-365. https://doi. org/10.1177/0165025407077757.

Lowe, P.A., Lee, S.W., Witteborg, K.M., Pritchard, K.W., Luhr, M.E., Cullinan, C.M., . . Janik, M. (2008). The test anxiety inventory for children and adolescents (TAICA): Examination of the psychometric properties of a new multidimensional measure of test anxiety among elementary and secondary school students. Journal of Psycheducational Assessment, 26(3), 215-230. https://doi.org/10.1177/0734282907303760 
Maguire, S. (2010). 'I just want a job'-what do we really know about young people in jobs without training? Journal of Youth Studies, 13(3), 317-333. https://doi.org/10.1080/13676260903447551.

Martin, A. (2002). Motivation and academic resilience: developing a model for student enhancement. Australian Journal of Education, 46(1), 34-49. https://doi.org/10.1177/000494410204600104.

Martin, A. J. (2007). Examining a multi-dimensional model of student motivation and engagement using a construct validation approach. British Journal of Educational Psychology, 77, 412-440. https://doi.org/ 10.1348/000709906X118036\#.

Martin, R. C., \& Dahlen, E. R. (2005). Cognitive emotion regulation in the prediction of depression, anxiety, stress, and anger. Personality and Individual Differences, 39(7), 1249-1260. https://doi.org/10.1016/j.paid.2005.06.004.

Martin, A. J., Marsh, H. W., \& Debus, R. L. (2001). Self-handicapping and defensive pessimism: exploring a model of predictors and outcomes from a self-protection perspective. Journal of Educational Psychology, 93, 87-102. https://doi.org/10.1037/0022-0663.93.1.87.

Martin, A. J., Marsh, H. W., Williamson, A., \& Debus, R. L. (2003). Self-handicapping, defensive pessimism, and goal orientation: a qualitative study of university students. Journal of Educational Psychology, 95(3), 617-628. https://doi.org/10.1037/0022-0663.95.3.617.

Matthews, G., Hillyard, E. J., \& Campbell, S. E. (1999). Metacognition and maladaptive coping as components of test anxiety. Clinical Psychology and Psychotherapy, 6(2), 111-125. https://doi.org/10.1002/(SICI)1099-0879(199905).

Murayama, K., Goetz, T., Malmerg, L.-E., Pekrun, R., Tanaka, A., \& Martin, A. J. (2017). Within-person analysis in educational psychology: importance and illustrations. In D. W. Putwain \& K. Smart (Eds.), The role of competence beliefs in teaching and learning (pp. 71-88). Leicester: The British Psychological Society.

Muthén, L. K., \& Muthén, B. O. (2017). Mplus user's guide (8th ed.). Los Angeles: Muthén \& Muthén.

O'Carroll, P. J., \& Fisher, P. (2013). Metacognitions, worry and attentional control in predicting OSCE performance. Medical Education, 47(6), 562-568. https://doi.org/10.1111/medu.12125.

Owens, M., Stevenson, J., Norgate, R., \& Hadwin, J. A. (2008). Processing efficiency theory in children: working memory as a mediator between trait anxiety and academic performance. Anxiety, Stress, \& Coping, 21(4), 417-430. https://doi.org/10.1080/10615800701847823.

Pekrun, R. (2006). The control-value theory of achievement emotions: assumptions, corollaries, and implications for educational research and practice. Educational Psychology Review, 18(4), 315-341. https://doi. org/10.1007/s10648-006-9029-9.

Pekrun, R., \& Perry, R. P. (2014). Control-value theory of achievement emotions. In R. Pekrun \& L. Linnenbrink-Garcia (Eds.), International handbook of emotions in education (pp. 120-141). New York: Routledge.

Pekrun, R., Goetz, T., Perry, R. P., Kramer, K., Hochstadt, M., \& Molfenter, S. (2004). Beyond test anxiety: development of the test emotions questionnaire (TEQ). Anxiety, Stress and Coping, 17(3), 287-316. https://doi.org/10.1080/10615800412331303847.

Plenty, S., \& Heubeck, B. G. (2013). A multidimensional analysis of changes in mathematics motivation and engagement during high school. Educational Psychology, 33(1), 14-30. https://doi.org/10.1080 /01443410.2012.740199.

Preiss, R. W., Gayle, B. M., \& Allen, M. (2006). Test anxiety, academic self-efficacy, and study skills: A metaanalytic review. In B. M. Gayle, R. W. Preiss, N. Burrell, \& M. Allen (Eds.), Classroom interaction and instructional processes: Advances through meta-analysis (pp. 99-111). Mahwah: Lawrence Erlbaum.

Putwain, D. W. (2007). Test anxiety in UK schoolchildren: prevalence and demographic patterns. British Journal of Educational Psychology, 77(3), 579-593. https://doi.org/10.1348/000709906X161704.

Putwain, D.W. (2008). Deconstructing test anxiety. Emotional and Behavioural Difficulties, 13(2), $141-155$. https://doi.org/10.1080/13632750802027713.

Putwain, D.W., \& Aveyard, B. (2018). Is perceived control a critical factor in understanding the negative relationship between cognitive test anxiety and examination performance? School Psychology Quarterly, 33(1), 65-74. https://doi.org/10.1037/spq0000183.

Putwain, D. W., \& Daly, A. L. (2014). Test anxiety prevalence and gender differences in a sample of English secondary school students. Educational Studies, 40(5), 554-570. https://doi.org/10.1080/03055698.2014.953914.

Putwain, D. W., \& Symes, W. (2012). Are low competence beliefs always associated with high test anxiety? The mediating role of achievement goals. British Journal of Educational Psychology, 82(2), 207-224. https://oi. org/10.1111/j.2044-8279.2011.02021.x.

Putwain, D. W., Woods, K. A., \& Symes, W. (2010). Personal and situational predictors of test anxiety of students in post-compulsory education. British Journal of Educational Psychology, 80(1), 137-160. https://doi.org/10.1348/000709909X466082.

Putwain, D. W., Langdale, H. C., Woods, K. A., \& Nicholson, L. J. (2011). Developing and piloting a dot-probe measure of attentional bias for test anxiety. Learning and Individual Differences, 21(4), 478-482. https://doi. org/10.1016/j.lindif.2011.02.002. 
Putwain, D. W., Symes, W., Connors, E., \& Douglas-Osborn, E. (2012). Is academic buoyancy anything more than adaptive coping? Anxiety, Stress and Coping, 25(3), 349-358. https://doi.org/10.1080 $/ 10615806.2011 .582459$.

Putwain, D. W., Shah, J., \& Lewis, R. (2014). Performance-evaluation threat does not always adversely affect verbal working memory in high test-anxious persons. Journal of Cognitive Education and Psychology, 13(1), 120-136. https://doi.org/10.1891/1945-8959.13.1.120.

Putwain, D. W., Daly, A. L., Chamberlain, S., \& Sadreddini, S. (2016). 'Sink or swim': buoyancy and coping in the cognitive test anxiety-academic performance relationship. Educational Psychology, 36(10), 1807-1825. https://doi.org/10.1080/01443410.2015.1066493.

Richards, A., French, C. C., Keogh, E., \& Carter, C. (2000). Test anxiety, inferential reasoning and working memory load. Anxiety, Stress and Coping, 13(1), 87-109. https://doi.org/10.1080/10615800008248335.

Richardson, M., Abraham, C., \& Bond, R. (2012). Psychological correlates of university students' academic performance: a systematic review and meta-analysis. Psychological Bulletin, 138(2), 353-387. https://doi.org/10.1037/a0026838.

Rost, D. H., \& Schermer, F. J. (1997). Differentielles Leistungsangst Inventar (DAI): Handbuch. [differential performance anxiety inventory: manual]. Frankfurt/Main: Swets Test Services.

Sarason, I. G. (1984). Stress, anxiety, and cognitive interference: reactions to tests. Journal of Personality and Social Psychology, 46(4), 929-938. https://doi.org/10.1037/0022-3514.46.4.929.

Sarason, I. G. (1988). Anxiety, self-preoccupation, and attention. Anxiety, Stress, and Coping, 1(1), 3-8. https://doi.org/10.1080/10615808808248215

Schwarzer, R. (1984). Worry and emotionality as separate components in test anxiety. International Review of Applied Psychology, 33(2), 205-220. https://doi.org/10.1111/j.1464-0597.1984.tb01429.x.

Segool, N. K., Nathaniel, P., Mata, A. D., \& Gallant, J. (2014). Cognitive behavioral model of test anxiety in a high-stakes context: an exploratory study. School Mental Health, 6(1), 50-61. https://doi.org/10.1007/s12310-013-9111-7.

Spielberger, C. D., \& Vagg, R.P. (1995). Test anxiety: A transactional process model. In C. D. Spielberger \& P. R. Vagg (Eds.) Test anxiety: Theory, assessment and treatment, edited (pp. 3-14). Bristol: Taylor \& Francis.

Srivastava, S., Tamir, M., McGonigal, K. M., John, O. P., \& Gross, J. J. (2009). The social costs of emotional suppression: a prospective study of the transition to college. Journal of Personality and Social Psychology, 96(4), 883-897. https://doi.org/10.1037/a0014755.

Steinmayr, R., Crede, J., McElvany, N., \& Wirthwein, L. (2016). Subjective well-being, test anxiety, academic achievement: testing for reciprocal effects. Frontiers in Psychology, 6, 1994. https://doi.org/10.3389 /fpsyg.2015.01994.

Stöber, J. (2004). Dimensions of test anxiety: relations to ways of coping with pre-exam anxiety and uncertainty. Anxiety, Stress and Coping, 17(3), 213-226. https://doi.org/10.1080/10615800412331292615.

Thomas, C. R., \& Gadbois, S. A. (2007). Academic self-handicapping: the role of self-concept clarity and students' learning strategies. British Journal of Educational Psychology, 77(1), 101-119. https://doi. org/10.1348/000709905X79644.

Thompson, R. A. (1994). Emotion regulation: a theme in search of definition. Monographs of the Society for Research in Child Development, 59(2/3), 25-52.

Topman, R. M., Kleijn, W., van der Ploeg, H. M., \& Masset, E. A. (1992). Test anxiety, cognitions, study habits and academic performance: A prospective study. In K. A. Hagtvet (Ed.), Advances in test anxiety research (Vol. 7, pp. 221-241). Amsterdam: Swets \& Zeitlinger.

Troy, A. S., Shallcross, A. J., \& Y Mauss, I. B. (2013). A person-by-situation approach to emotion regulation: cognitive reappraisal can either help or hurt, depending on the context. Psychological Science, 24(12), 25052514. https://doi.org/10.1177/0956797613496434.

Unwin, L. (2010). Learning and working from the MSC to New Labour: young people, skills and employment. National Institute Economic Review, 212(1), R49-R60. https://doi.org/10.1177/0027950110372443.

von der Embse, N. P., Jester, D., Roy, D., \& Post, J. (2018). Test anxiety effects, predictors, and correlates: a 30-year meta-analytic review. Journal of Affective Disorders, 227, 483-493. https://doi.org/10.1016/j.jad.2017.11.048.

Wine, J. D. (1971). Test anxiety and the direction of attention. Psychological Bulletin, 76(2), 92-104. https://doi. org/10.1037/h0031332

Zeidner, M. (1998). Test anxiety: The state of the art. New York: Plenum.

Zeidner, M. (2014). Anxiety in education. In R. Pekrun \& L. Linnenbrink-Garcia (Eds.), International handbook of emotions in education (pp. 265-288). New York: Routledge.

Zeidner, M., \& Matthews, G. (2005). Evaluation anxiety. In A. J. Elliot \& C. S. Dweck (Eds.), Handbook of competence and motivation (pp. 141-163). London: Guilford Press. 
David W. Putwain. School of Education, Liverpool John Moores University, IM Marsh Campus, Mossley Hill Rd, Liverpool, L17 6DB. Email D.W.Putwain@ljmu.ac.uk

Current themes of research:

Emotions. Test anxiety. Wellbeing. Classroom environment.

Most relevant publications in the field of Psychology of Education:

Putwain, D.W., Nakhla, G., Liversidge, A., Nicholson, L.J., Porter, B., \& Reece, M. (2017). Teachers use of fear appeals prior to a high-stakes examination: Is frequency linked to perceived student engagement and how do students respond? Teaching and Teacher Education, 61, 73-83.doi: 10.1016/j.tate.2016.10.003

Putwain, D.W., Symes, W., \& Wilkinson, H.M. (2017). Fear appeals, engagement, and examination performance: The role of challenge and threat appraisals. British Journal of Educational Psychology, 87(1), 16-

31.doi: 10.1011./bjep.12132

McGeown, S.P., St.Clair-Thompson, H., Putwain, D.W. (2017). Understanding and supporting adolescents' mental toughness in an education context. Psychology in the Schools, 54(2), 196-209.doi: 10.1002/ pits. 21986

St.Clair-Thompson, H., McGeown, S.P., Putwain, D.W., Clough, P., \& Perry, J. (2017). Mental toughness and transitions to high school and to undergraduate study. Educational Psychology, 37(7), 792-809. doi: 10.1080/01443410.2016.1184746

Putwain, D.W. \& Smart, K. (2017). Monograph Series II: Psychological Aspects of Education-Current Trends: The Role of Competence Beliefs in Teaching and Learning. Leicester: British Psychological Society.

McGeown, S.P., St.Clair-Thompson, H., Putwain, D.W. (2018). The development and validation of a mental toughness scale for adolescents. Journal of Psychoeducational Assessment, 36(2) 148-161.doi: 10.1177/ 0734282916673512

Nicholson, L.J., \& Putwain, D.W. (2018). The importance of psychological need satisfaction in educational reengagement. Research Papers in Education, 33(2), 169-186.doi: 10.1080/02671522.2016.1271004

Putwain, D.W., \& Aveyard, B. (2018). Is perceived control a critical factor in understanding the negative relationship between cognitive test anxiety and examination performance? School Psychology Quarterly, 33(1), 65-74. doi: 10.1037/spq0000183

Putwain, D.W., Becker, S., Symes, W., \& Pekrun, R. (2018). Reciprocal relations between academic Enjoyment, boredom, and achievement over time. Learning and Instruction, 54, 73-81.doi: 10.1016/ j.learninstruc.2017.08.004

Flitcroft, D., Woods, K., \& Putwain, D. W. (In press). Developing school practice in preparing students for highstake examinations in English and Mathematics. Educational \& Child Psychology.

Putwain, D.W., Becker, S., Symes, W., \& Pekrun, R. (In press). Reciprocal relations between academic enjoyment, boredom, and achievement over time. Learning and Instruction.doi: 10.1016/

j.learninstruc.2017.08.004

Putwain, D.W., \& Prescod, M. (In press). Is reducing uncertain control the key to successful test anxiety for secondary school students? Findings from a randomized control trial. School Psychology Quarterly. 